\title{
Hardening effect of pre- and post-firing heat treatment for a firing-simulated Au-Pd-In metal-ceramic alloy
}

\author{
Byung-Wook Jeon • Sung-Min Kim • Hyung-Il Kim • \\ Yong Hoon Kwon • Hyo-Joung Seol
}

Published online: 19 August 2014

(C) The Author(s) 2014. This article is published with open access at SpringerLink.com

\begin{abstract}
The hardening effect of the pre- and post-firing heat treatments and their dual treatment was examined for a firingsimulated Au-Pd-In metal-ceramic alloy to determine if an additional post-firing heat treatment is effective in the hardening of an Au-Pd-In metal-ceramic alloy as well as to compare the hardening effects of pre- and post-firing heat treatments for a firing-simulated Au-Pd-In metal-ceramic alloy. The postfiring heat treatment was much more effective than the prefiring heat treatment or dual treatments. The hardening effect of the pre- and post-firing heat treatments was caused by the induction of fine grain interior precipitation. In the pre-firing heat-treated specimen after casting, the apparent hardening was achieved during simulated porcelain firing, but an additional post-firing heat treatment did not introduce severe grain interior precipitation, resulting in very weak hardening. In the as-cast specimen without the pre-firing heat treatment, apparent hardening by grain interior precipitation was achieved only by post-firing heat treatment and not by simulated porcelain firing.
\end{abstract}

Keywords Pre-firing heat treatment $\cdot$ Post-firing heat treatment · Au-Pd-In metal-ceramic alloy · Porcelain firing simulation · Grain interior precipitation

\section{Introduction}

Metal-ceramic gold alloys are used to fabricate substructures of porcelain, and thus, the metal substructures are made thin enough to increase the aesthetic potential of semitranslucent

B.-W. Jeon • S.-M. Kim • H.-I. Kim • Y. H. Kwon • H.-J. Seol ( $ه)$ Department of Dental Materials, Institute of Translational Dental Sciences, School of Dentistry, Pusan National University,

Beomeo-Ri, Mulgeum-Eup, Yangsan-Si, Gyeongsangnam-Do 626-814, South Korea

e-mail: seolhyojoung@daum.net porcelain superstructure [1,2]. Metal-ceramic gold alloys have insufficient creep resistance and poor hardness after casting due to the high gold content. In addition, these alloys are heat treated several times at high temperatures for porcelain firing after casting. During this process, these alloys can be deformed by sag and thermal distortion [3, 4]. This causes serious problems, such as an inaccurate fit of the restoration $[5,6]$. To resolve this problem, studies of heat treatments before porcelain firing have been conducted with a purpose to increase the hardness of metal-ceramic gold alloys before porcelain firing [7-9]. Koike reported that if a casting is pre-heated near the porcelain firing temperature before surface grinding, distortion from subsequent procedures can be controlled remarkably [7]. Liu and Wang reported that pre-firing heat treatment increased the hardness of Pd-free Au-Pt metal-ceramic gold alloy [8]. They attributed the strengthening to the homogenization of the microstructure and the precipitation of new fine particles. Fischer and Fleetwood reported that pre-firing heat treatment improved the processing of Au-Pt metal-ceramic frameworks by increasing the hardness, resistance to thermal distortion and proof stress [9].

The strength of metal ceramics depends largely on the strength of the metal substructure. Accordingly, porcelain fractures even by slight deformation of the metal substructure after the completion of fusion bonding [1]. Therefore, if the hardness of the metal-ceramic gold alloys is insufficient even after a pre-firing heat treatment, the fracture or separation of porcelain can occur during mastication. From such a viewpoint, it was considered that additional post-firing heat treatment at relatively lower temperatures might increase the hardness of the metal substructure without softening or damaging the porcelain. In the present study, the hardening effect of preand post-firing heat treatments and their dual treatment on a firing-simulated Au-Pd-In metal-ceramic alloy was examined. The aims of the present investigation were to determine if an 
additional post-firing heat treatment is effective in hardening an Au-Pd-In metal-ceramic alloy and to compare the hardening effects of pre- and post-firing heat treatments for a firingsimulated Au-Pd-In metal-ceramic alloy.

\section{Materials and methods}

Specimen alloy

The specimen alloy used in this study was a $\mathrm{Cu}$-free $\mathrm{Au}-\mathrm{Pd}-\mathrm{In}$ metal-ceramic alloy (Aurolite 45, Aurium research, USA) with a white colour and fine grain, which belongs to type IV. The manufacturer reported the alloy to have a melting range of $1,190 \sim 1,290{ }^{\circ} \mathrm{C}$ and a casting temperature of $1,370{ }^{\circ} \mathrm{C}$. Table 1 lists the chemical composition of the alloy. The specimens were cast using the lost wax casting technique in a standard broken arm centrifugal casting machine (Centrifugal casting machine, Osung, Korea). All castings were bench cooled to room temperature, followed by divesting and airborne-particle abrasion with $50 \mu \mathrm{m} \mathrm{Al}_{2} \mathrm{O}_{3}$. The specimens obtained were in the form of small square pieces, $10 \times 10 \times 0.8 \mathrm{~mm}$ in size.

\section{Heat treatment}

The above-mentioned as-cast plate-like specimens were prefiring heat treated at $980{ }^{\circ} \mathrm{C}$ for $10 \mathrm{~min}$ in a vertical electric furnace under an argon atmosphere to inhibit oxidation and then quenched rapidly by dropping it into ice brine to prevent hardening by atomic diffusion. The specimens were then heat treated in a ceramic furnace (Multimat 2 touch, Dentsply, Germany) to simulate the complete firing cycle according to Table 2. An additional post-firing heat treatment was performed in a ceramic furnace that was adjusted to 550 or $650{ }^{\circ} \mathrm{C}$.

\section{Hardness test}

Hardness measurements were completed for the required heattreated specimen using a Vickers microhardness tester (MVKH1, Akashi Co., Japan) with 300 gf and dwell time of 10 s. All hardness results were recorded as the mean values of five measurements.

Table 1 Chemical composition of the specimen

\begin{tabular}{lllllll}
\hline Composition & $\mathrm{Au}$ & $\mathrm{Pd}$ & $\mathrm{In}$ & $\mathrm{Ag}$ & $\mathrm{Ga}$ & $\mathrm{Ru}$ \\
\hline wt.\% & 45.00 & 40.00 & 8.50 & 4.90 & 1.50 & 0.10 \\
at.\% & 30.61 & 50.37 & 9.92 & 6.09 & 2.88 & 0.13 \\
\hline
\end{tabular}

Table 2 Simulated porcelain firing cycle

\begin{tabular}{lllllll}
\hline $\begin{array}{l}\text { Firing } \\
\text { stage }\end{array}$ & $\begin{array}{l}\text { Start } \\
\text { temp. } \\
\left({ }^{\circ} \mathrm{C}\right)\end{array}$ & $\begin{array}{l}\text { Pre-drying } \\
(\mathrm{min})\end{array}$ & $\begin{array}{l}\text { Heat rate } \\
\left({ }^{\circ} \mathrm{C} / \mathrm{min}\right)\end{array}$ & $\begin{array}{l}\text { Final } \\
\text { temp. } \\
\left({ }^{\circ} \mathrm{C}\right)\end{array}$ & $\begin{array}{l}\text { Time at } \\
\text { final temp. } \\
(\mathrm{min})\end{array}$ & $\begin{array}{l}\text { Vacuum } \\
\text { time }(\mathrm{min})\end{array}$ \\
\hline Degassing & 650 & 0 & 70 & 1,010 & 0 & 0 \\
Wash & 550 & 2 & 70 & 980 & 1 & $7: 09$ \\
Opaque & 550 & 3 & 70 & 970 & 1 & $7: 00$ \\
Main bake & 550 & 5 & 70 & 960 & 1 & $6: 51$ \\
Correction & 550 & 4 & 70 & 950 & 1 & $6: 43$ \\
Glaze & 550 & 1 & 70 & 910 & 1 & 0 \\
\hline
\end{tabular}

Field emission scanning electron microscopy (FE-SEM)

For FE-SEM (JSM-6700 F, Jeol, Japan), the as-cast plate-like specimens were subjected to the required heat treatment and prepared using a standard metallographic technique. Subsequently, a freshly prepared aqueous solution of $10 \%$ potassium cyanide $(\mathrm{KCN})$ and $10 \%$ ammonium persulfate $\left(\left(\mathrm{NH}_{4}\right)_{2} \mathrm{~S}_{2} \mathrm{O}_{8}\right)$ was used for final etching of the specimens. The specimens were examined by FE-SEM at $15 \mathrm{kV}$.

X-ray diffraction (XRD) study

For XRD (XPERT-PRO, Philips, Netherlands), the as-cast plate-like specimens were subjected to the required heat treatment and prepared using a standard metallographic technique. The XRD profile was recorded at $40 \mathrm{kV}$ and $30 \mathrm{~mA}$ using nickel-filtered $\mathrm{Cu} \mathrm{K} \alpha$ radiation as the incident beam. The scanning rate of a goniometer was $1^{\circ}(2 \theta / \mathrm{min})$.

Energy dispersive spectrometer (EDS) analysis

The changes in the element distribution of the heat-treated plate-like specimens with heat treatment were examined using an energy dispersive X-ray spectrometer (INCA X-sight, Oxford Instruments Ltd., UK) attached to the FE-SEM at $15 \mathrm{kV}$.

\section{Results and discussion}

Hardness changes at various cooling rates during porcelain firing simulation

Metal-ceramic gold alloys can be hardened during cooling after porcelain firing $[9,10]$, and the hardness of a metal-ceramic gold alloy can be increased significantly by controlling the cooling rate. To identify the most effective cooling rate for hardening of the alloy, the specimens underwent cooling at various cooling rates during the degassing treatment, which is the first stage of the porcelain firing cycle. Tables 2 and 3 list 
Table 3 Cooling rate during simulated firing

\begin{tabular}{lllllll}
\hline $\begin{array}{l}\text { Cooling } \\
\text { rate }\end{array}$ & Ice quenching & Quick cooling & Stage 0 & Stage 1 & Stage 2 & Stage 3 \\
\hline Condition & $\begin{array}{c}\text { Quenching into } \\
\text { ice brine }\end{array}$ & $\begin{array}{c}\text { Firing chamber moves } \\
\text { immediately to upper } \\
\text { end position and air cooled }\end{array}$ & $\begin{array}{c}\text { Firing chamber moves } \\
\text { immediately to upper } \\
\text { end position }\end{array}$ & $\begin{array}{c}\text { Firing chamber } \\
\text { opens about } \\
70 \mathrm{~mm}\end{array}$ & $\begin{array}{c}\text { Firing chamber } \\
\text { opens about } \\
50 \mathrm{~mm}\end{array}$ & $\begin{array}{c}\text { Firing chamber } \\
\text { remains closed }\end{array}$ \\
\hline
\end{tabular}

the simulated porcelain firing cycle and each cooling rate, respectively. The degassing schedule was directed by the alloy manufacturer. To obtain a single-phase specimen before the firing simulation, as-cast specimens were prefiring heat treated at $980{ }^{\circ} \mathrm{C}$ for $10 \mathrm{~min}$ and ice quenched. The hardness was $207.0 \pm 1.18 \mathrm{HV}$ in this state. The specimens were then degassing treated and cooled to $600{ }^{\circ} \mathrm{C}$ at six cooling rates in a porcelain furnace and then bench cooled to room temperature. Table 4 lists the hardness at each cooling rate during the simulated degassing treatment. The specimen cooled by ice quenching showed the lowest hardness, $202.6 \mathrm{HV}$, which is similar to that of the pre-firing heat-treated specimen. Therefore, the ice-quenched specimen after degassing was believed to be single phase. The specimen cooled by quick cooling showed the highest hardness, $255.1 \mathrm{HV}$. As the cooling rate becomes slower than quick cooling, the increasing rate in hardness decreased gradually. Therefore, the cooling rate during simulated porcelain firing was fixed to quick cooling in the present study.

Hardening effect of the pre- and post-firing heat treatments

To observe the effects of a pre-firing heat treatment on the hardness of a porcelain firing-simulated specimen, the changes in hardness by simulated porcelain firing of the as-cast and pre-firing heat-treated specimens were examined. Figure 1 shows the changes in hardness during simulated porcelain firing at a fixed cooling rate (quick cooling) in the as-cast and pre-firing heat-treated specimens. In the as-cast state, the hardness was approximately $220 \mathrm{HV}$, which was not changed apparently by the degassing and wash treatments. Subsequently, the hardness increased to the maximum value, $252.0 \mathrm{HV}$, by an opaque treatment. By the subsequent simulated firing schedule of the main bake, correction and glaze, the hardness decreased gradually and finally became similar to that of the as-cast state (226.9 HV). From the above, the porcelain firing full cycle did not result in hardening of the as-cast specimen [11], unlike the case of the $\mathrm{Au}-\mathrm{Pt}$ and $\mathrm{Au}-\mathrm{Pd}-\mathrm{Ag}$ metal-ceramic alloys $[9,10,12]$.

After the pre-firing heat treatment after casting, the hardness decreased to $207 \mathrm{HV}[10,13]$. On the other hand, the hardness increased to $255 \mathrm{HV}$ after the degassing treatment, the first firing stage, and the high hardness was maintained during the subsequent firing stages. Therefore, the pre-firing heat treatment itself softens the as-cast specimen but results in apparent hardening from the first stage of firing with softening restrained until the final firing stage. From a clinical point of view, the hardening of a metal-ceramic alloy during porcelain firing is advantageous because it improves the fit of the restoration by reducing the level of sag [9], which can be obtained by a pre-firing heat treatment.

To determine the hardening effect of the post-firing heat treatment on firing the simulated specimen, the as-cast specimen and pre-firing heat-treated specimen were post-firing heat treated in a porcelain furnace after firing. Figure 2 shows the changes in hardness of the as-cast and pre-firing heattreated specimen during post-firing heat treatment at 550 and $650{ }^{\circ} \mathrm{C}$. Here, $550{ }^{\circ} \mathrm{C}$ is the hardening temperature recommended by the alloy manufacturer. In the as-cast specimen marked by black, the hardness increased by $54 \mathrm{HV}$ within $20 \mathrm{~min}$ at both temperatures. After that, however, the hardness decreased with increasing heating time. The decreasing rate was faster at $650{ }^{\circ} \mathrm{C}$ than at $550{ }^{\circ} \mathrm{C}$ due to the faster atomic diffusion at a higher temperature [14].

In the pre-firing heat-treated specimen after casting, which is marked as white, the hardening effect of the post-firing heat treatment was relatively weak. In Fig. 2, the hardness increased slightly by $13 \mathrm{HV}$ within $15 \mathrm{~min}$ and the hardness then decreased gradually. The decreasing rate was faster at $650{ }^{\circ} \mathrm{C}$ than at $550{ }^{\circ} \mathrm{C}$, as it was in the as-cast specimen without the pre-firing heat treatment. These results show that the post-firing heat treatment was much more effective than

Table 4 Hardness at each cooling rate during simulated degassing treatment

\begin{tabular}{lllllll}
\hline Cooling rate & Ice quenching & Quick cooling & Stage 0 & Stage 1 & Stage 2 & Stage 3 \\
\hline Hardness (HV) & $202.6( \pm 2.67)$ & $255.1( \pm 4.36)$ & $243.6( \pm 2.97)$ & $237.9( \pm 2.35)$ & $224.1( \pm 4.77)$ & $210.4( \pm 4.67)$ \\
\hline
\end{tabular}




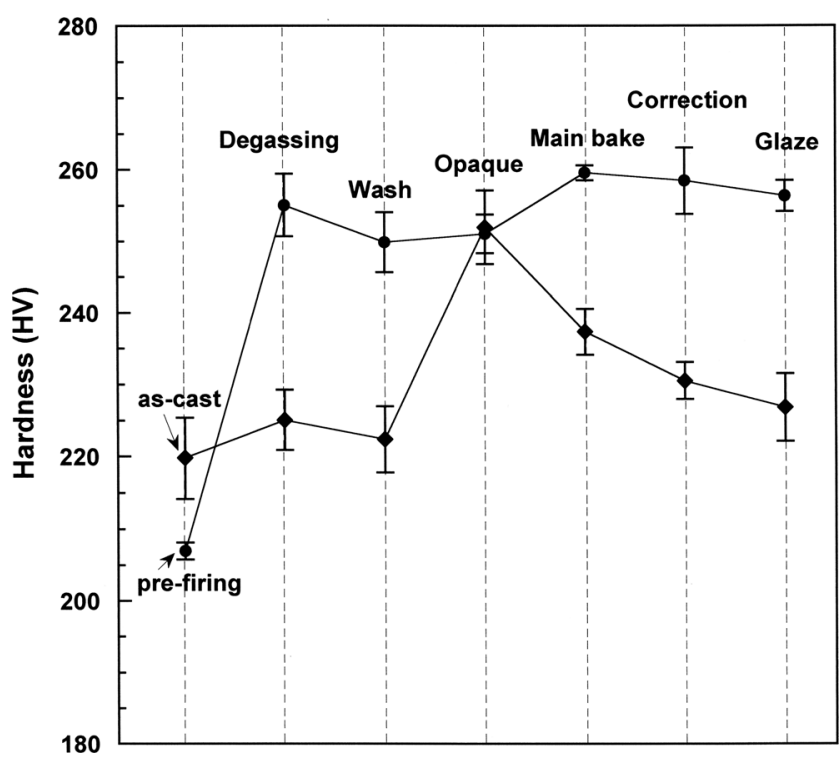

Fig. 1 Hardness changes in the as-cast and pre-firing heat-treated specimen during simulated complete firing

the pre-firing heat treatment (Fig. 1) or pre- and post-firing dual heat treatment (Fig. 2, white mark) for hardening of the Au-Pd-In metal-ceramic alloy.

Microstructural changes by simulated porcelain firing and post-firing heat treatment

The microstructural changes of the as-cast and pre-firing heattreated specimens by simulated porcelain firing were observed by FE-SEM. Figure 3 shows FE-SEM images of the as-cast specimen (a), as-cast and then porcelain firing-simulated

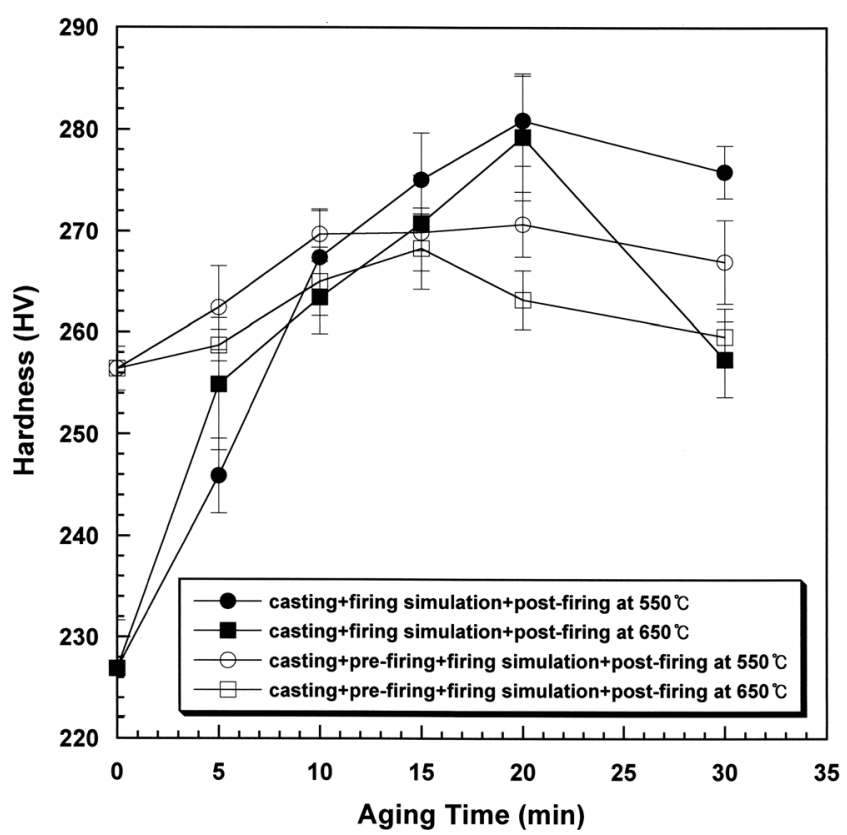

Fig. 2 Hardness changes in the as-cast and pre-firing heat-treated specimen during post-firing heat treatment at 550 and $650{ }^{\circ} \mathrm{C}$ specimen (b), pre-firing heat-treated specimen after casting (c) and the as-cast and then pre-firing and porcelain firingsimulated specimen (d) at magnifications of $\times 2,500$ (1), $\times 8,000$ (2) and $\times 35,000$ (3). In the as-cast specimen (a), in addition to the equiaxed structure and grain boundary precipitates, lamellar and cubic- or particle-like structures were observed adjacent to the grain boundaries. By subsequent porcelain firing simulation (b), the grain boundary precipitates became partly narrow, and the lamellar structures observed adjacent to the grain boundaries disappeared. The fine cubicor particle-like structures became smaller and spread toward the grain interior. Grain interior precipitates were not observed in the matrix marked by the circle in (b-3).

In the pre-firing heat-treated specimen after casting (c), there was no precipitate in the grain interior and grain boundaries, and only a single-phased equiaxed structure was observed, resulting in a $15 \mathrm{HV}$ decrease in hardness from the ascast state. By subsequent porcelain firing simulation (d), precipitates formed along the grain boundaries and cubic- or particle-like structures were observed in the whole grain interior, as it was in the porcelain firing-simulated specimen after casting (b). On the other hand, unlike the microstructures of (b), fine grain interior precipitates were observed in the matrix marked by the circle at (d-3). Therefore, the hardening effect of the pre-firing heat treatment on simulated porcelain firing was caused by the induction of the grain interior precipitation of fine scale, as can be seen by a comparison of (d-3) with (b-3).

Microstructural changes by post-firing heat treatment of the as-cast and pre-firing heat-treated specimens were observed. Figure 4 shows FE-SEM images of the porcelain firing simulated and then post-firing heat-treated specimens at $550{ }^{\circ} \mathrm{C}$ for $30 \mathrm{~min}$ after casting (a) and after casting and pre-firing heat treatment (b) at magnifications of $\times 2,500(1), \times 8,000(2)$ and $\times$ 35,000 (3). In specimen (a), the grain boundary precipitates and cubic- or particle-like structures in the grain interior became coarse compared to those before the post-firing heat treatment in Fig. 3(b), and the lamellar structures appeared. Therefore, the microstructure became partly similar to that of the as-cast specimen in Fig. 3(a) except for the spread of cubic or particle-like structures to the grain interior. The decisive difference in microstructure by post-firing was that the fine grain interior precipitates covered the entire matrix region, as shown in a circle mark of Fig. 4(a-3). This must be the main reason for the apparent increase in hardness by post-firing heat treatment in the firing-simulated specimen after casting. This hardening mechanism by grain interior precipitation was similar to that by the pre-firing heat treatment, as shown in the circle mark of Fig. 3(d-3).

In the pre-firing heat-treated specimen after casting (b), no obvious microstructural differences, particularly in the matrix, were observed after the post-firing heat treatment, as can be seen by a comparison of the circle-marked region in 

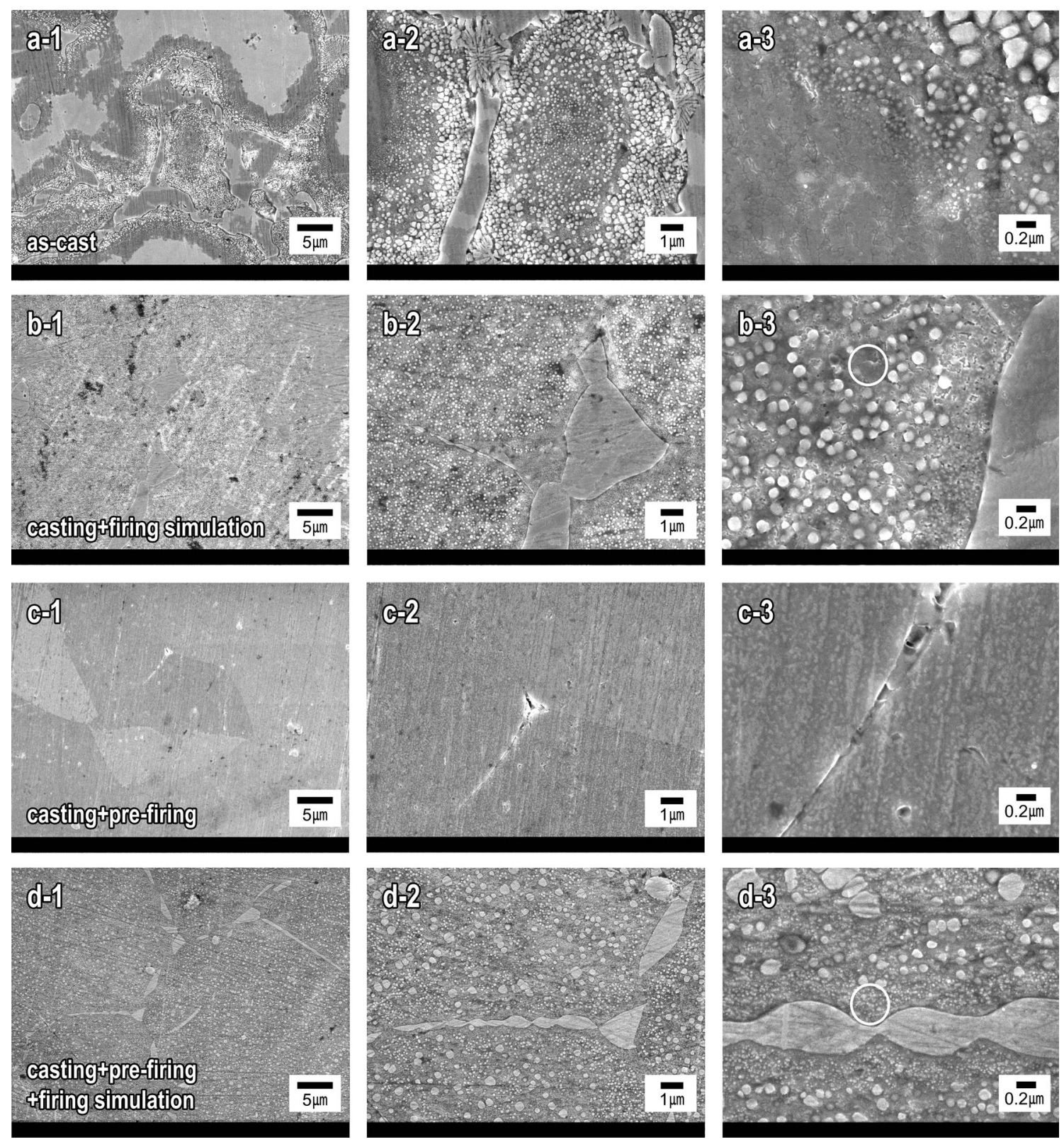

Fig. 3 Microstructural changes in the as-cast and pre-firing heat-treated specimen by simulated complete firing: as-cast $(a)$, firing simulated after casting $(b)$, pre-firing heat-treated after casting $(c)$ and firing simulated

after casting and pre-firing heat treatment $(d)$ at magnifications of $\times 2,500$ $(1), \times 8,000(2)$ and $\times 35,000(3)$

Fig. 4(b-3) with that in Fig. 3(d-3). In the pre-firing heattreated specimen after casting, apparent hardening by grain interior precipitation was achieved during simulated porcelain firing, but an additional post-firing heat treatment did not introduce severe grain interior precipitation, resulting in very weak hardening.

Phase transformation and elemental distribution

Figure 5 shows the changes in the XRD patterns of the as-cast and pre-firing heat-treated specimen after simulated complete firing and post-firing heat treatment at $550^{\circ} \mathrm{C}$ for $30 \mathrm{~min}$ (a, as cast; $b$, pre-firing heat treated after casting; $c$, simulated complete firing; $d$, post-firing heat treated). In the as-cast specimen (a), a face-centred cubic (f.c.c.) Pd-Au-rich $(\alpha)$ phase with a lattice parameter of $a_{200}=3.9958 \AA$ was the main phase and another phase marked by arrows was a minor phase due to the precipitates. The XRD pattern of the as-cast specimen did not change by subsequent simulated complete firing, $(\mathrm{a}+\mathrm{c})$ and post-firing heat treatment, $(\mathrm{a}+\mathrm{c}+\mathrm{d})$. In the pre-firing heattreated specimen after casting (b), a single f.c.c. Pd-Au-rich $\left(\alpha_{0}\right)$ phase with a lattice parameter of $a_{200}=3.9931 \AA$ was obtained. By subsequent simulated complete firing, $(b+c)$, and post-firing heat treatment, $(\mathrm{b}+\mathrm{c}+\mathrm{d})$, a minor phase 

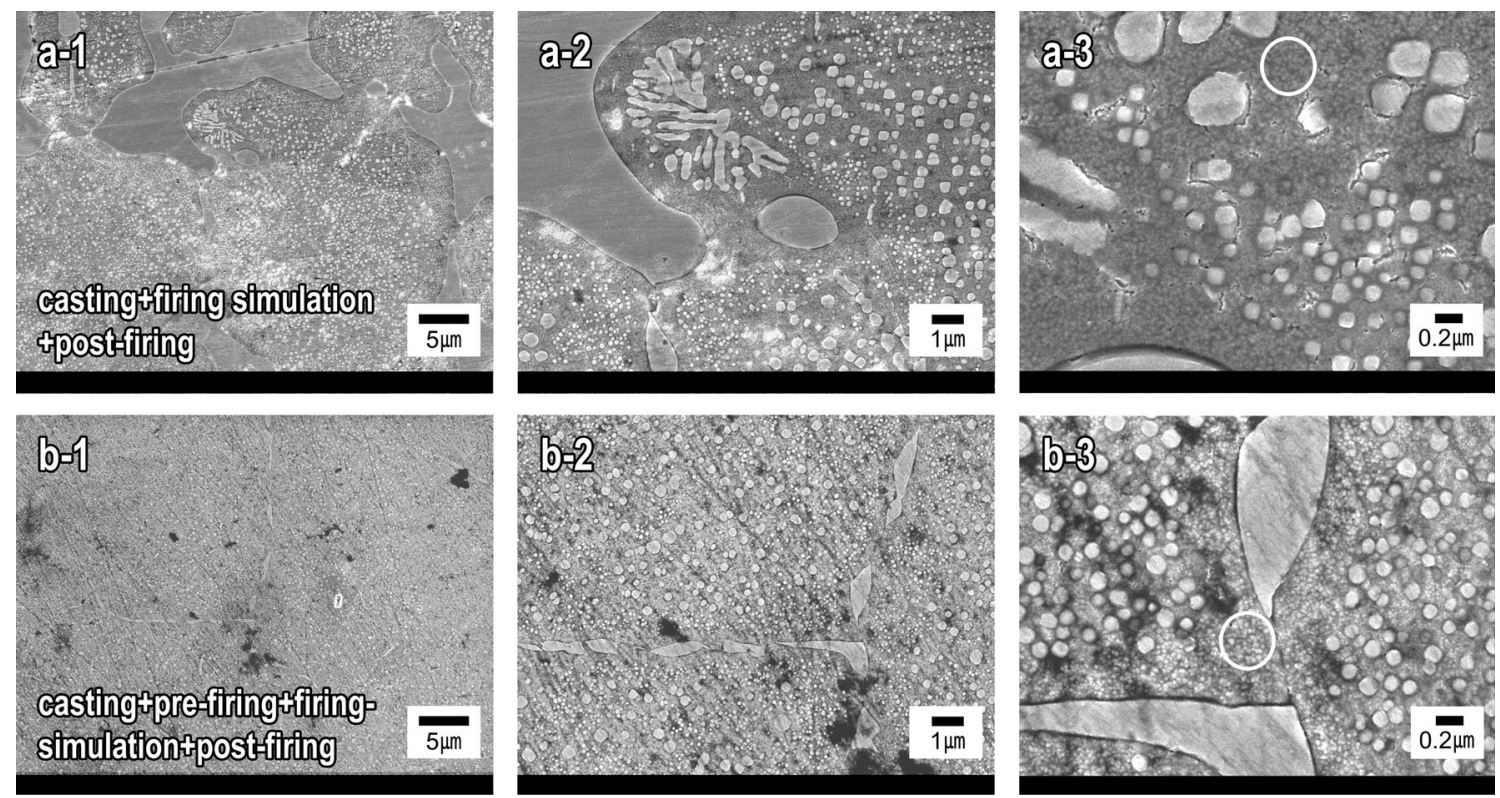

Fig. 4 Microstructural changes in the as-cast and pre-firing heat-treated specimen by post-firing heat treatment at $550{ }^{\circ} \mathrm{C}$ for $30 \mathrm{~min}$ : post-firing heat treated after casting and firing simulation $(a)$, post-firing heat treated

marked by the arrows was newly formed by precipitation. Its peak position was same as that of the as-cast specimen (a), indicating it to be the same phase.

EDS analysis was performed to identify the precipitated elements during the above-mentioned heat treatment. Figure 6 presents an FE-SEM image of the porcelain firing simulated

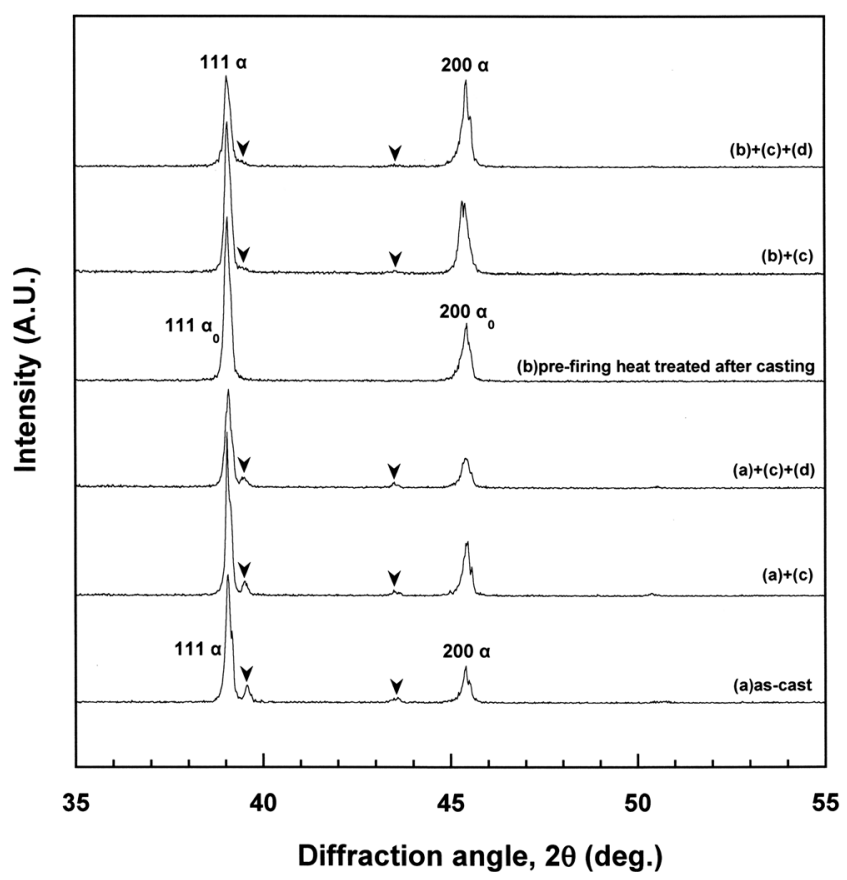

Fig. 5 Changes in the XRD patterns of the as-cast and pre-firing heattreated specimen after simulated complete firing and post-firing heat treatment at $550{ }^{\circ} \mathrm{C}$ : as-cast (a), pre-firing heat treated after casting (b), simulated complete firing (c), post-firing heat treated (d) after casting, pre-firing and firing simulation $(b)$ at magnifications of $\times 2,500(1), \times 8,000(2)$ and $\times 35,000(3)$

and the post-firing heat-treated specimen at $650{ }^{\circ} \mathrm{C}$ for $30 \mathrm{~min}$ after casting and pre-firing heat treatment $(\mathrm{M}$, matrix; $\mathrm{P}$, grain interior precipitate; $\mathrm{Gb}$, grain boundary precipitate at a magnification of $\times 7,000$ ). Table 5 lists the results of EDS point analysis for each region marked with the arrow in Fig. 6.

In the solute-depleted matrix region, which is covered by grain interior precipitates, $(\mathrm{M}+\mathrm{P})$, the composition was similar to the alloy composition in Table 1. In the grain boundary precipitate (Gb), Au and Ag decreased and Pd, Ga and In increased compared to the alloy composition. In particular, the Ga content increased to more than twice that of the alloy composition. By considering the elemental distribution in the grain boundary precipitate, the precipitated phase was possibly the ordered $\mathrm{Ga}_{2} \mathrm{Pd}_{5}$ phase containing In [15]. From the above, it was believed that precipitation and then ordering of $\mathrm{Pd}$, Ga and In occurred by simulated porcelain firing and post-firing heat treatment, resulting in apparent hardening.

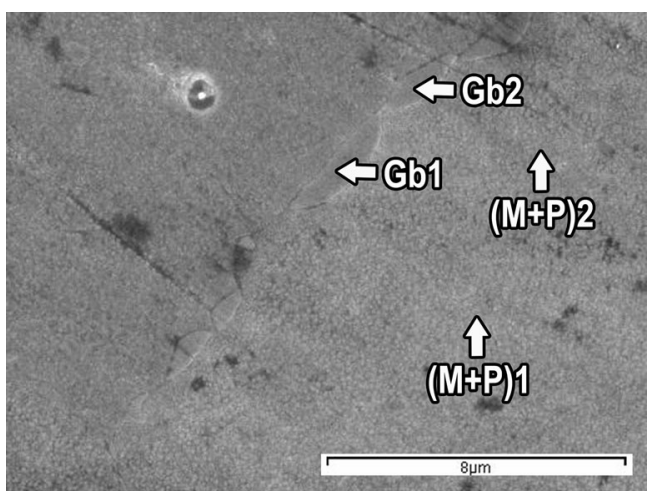

Fig. 6 FE-SEM images of the post-firing heat-treated specimens at $650{ }^{\circ} \mathrm{C}$ for $30 \mathrm{~min}$ for EDS analysis 
Table 5 EDS analysis at the regions marked in Fig. 6

\begin{tabular}{lllllll}
\hline at.\% & $\mathrm{Au}$ & \multicolumn{1}{l}{$\mathrm{Pd}$} & \multicolumn{1}{l}{ In } & $\mathrm{Ag}$ & $\mathrm{Ga}$ & $\mathrm{Ru}$ \\
\hline$(\mathrm{M}+\mathrm{P}) 1$ & 32.54 & 51.22 & 9.08 & 4.79 & 2.37 & 0 \\
$(\mathrm{M}+\mathrm{P}) 2$ & 30.76 & 51.54 & 10.58 & 3.73 & 3.39 & 0 \\
$\mathrm{~Gb} 1$ & 22.38 & 58.47 & 11.54 & 0 & 7.61 & 0 \\
$\mathrm{~Gb} 2$ & 23.03 & 58.10 & 12.01 & 0 & 6.86 & 0 \\
\hline
\end{tabular}

\section{Conclusions}

The hardening effect of the pre- and post-firing heat treatments and their dual treatment was examined for a firing-simulated Au-Pd-In metal-ceramic alloy to determine if an additional post-firing heat treatment is effective in the hardening of an Au-Pd-In metal-ceramic alloy as well as to compare the hardening effects of preand post-firing heat treatments for a firing-simulated Au-Pd-In metal-ceramic alloy.

(1) The post-firing heat treatment was much more effective than the pre-firing heat treatment or pre- and post-firing dual heat treatment for the hardening of an Au-Pd-In metal-ceramic alloy.

(2) The hardening effect of pre- and post-firing heat treatments was caused by the induction of the grain interior precipitation of fine scale.

(3) In the pre-firing heat-treated specimen after casting, the apparent hardening was achieved during simulated porcelain firing, but an additional postfiring heat treatment did not introduce severe grain interior precipitation, resulting in very weak hardening.

(4) In the as-cast specimen without the pre-firing heat treatment, apparent hardening by grain interior precipitation was achieved only by post-firing heat treatment and not by simulated porcelain firing.

Acknowledgments This research was supported by Basic Science Research Program through the National Research Foundation of Korea
(NRF) funded by the Ministry of Education, Science and Technology (grant number: 2011-0010995)

Open Access This article is distributed under the terms of the Creative Commons Attribution License which permits any use, distribution, and reproduction in any medium, provided the original author(s) and the source are credited.

\section{References}

1. Yamamoto M (1985) Metal-ceramics: principle and methods of Makoto Yamamoto. Quintessence Publishing Co Inc, Chicago, pp 23-25, Chap 1

2. Straussberg G, Katz G, Kuwata M (1966) Design of gold supporting structures for fused porcelain restorations. J Prosthet Dent 16:928-936

3. Chew CL, Norman RD, Stewart GP (1990) Mechanical properties of metal-ceramic alloys at high temperature. Dent Mater 6:223-227

4. O'Brien WJ (2002) Dental materials and their selection, 3rd edn. Quintessence Publishing Co Inc, Chicago, p 204, Chap 14

5. Tuccillo JJ, Nielsen JP (1967) Creep and sag properties of a porcelain-gold alloy. J Dent Res 46:579-583

6. Iwashita H, Kuriki H, Hasuo T, Ishikawa K, Hashimoko K, Harada H, Uochi T, Hata Y (1977) Studies on dimensional accuracy of porcelain fused to precious metal crown: the influence of the porcelain to the metal coping on the porcelain fusing procedure. Shigaku 65:110-125

7. Koike K (1997) Fabrication of ceramo-metal crowns with accurate fitness: deformation of casting and its remedies. Shika Giko 5:31-41

8. Wang JN, Liu WB (2006) A Pd-free high gold dental alloy for porcelain bonding. Gold Bull 39:114-120

9. Fischer J, Fleetwood PW (2000) Improving the processing of highgold metal-ceramic frameworks by a pre-firing heat treatment. Dent Mater 16:109-113

10. German RM (1980) Hardening reactions in a high-gold content ceramo-metal alloy. J Dent Res 59:1960-1965

11. Li D, Baba N, Brantley WA, Alapati SB, Heshmati RH, Daehn GS (2010) Study of Pd-Ag dental alloys: examination of effect of casting porosity on fatigue behavior and microstructural analysis. J Mater Sci Mater Med 21:2723-2731

12. Vermilyea SG, Huget EF, Vilca JM (1980) Observations on goldpalladium-silver and gold-palladium alloys. J Prosthet Dent 44:294-299

13. Watanabe I, Watanabe E, Cai Z, Okabe T, Atsuta M (2001) Effect of heat treatment on mechanical properties of age-hardenable gold alloy at intraoral temperature. Dent Mater 17:388-393

14. Jeon GH, Kwon YH, Seol HJ, Kim HI (2008) Hardening and overaging mechanisms in an $\mathrm{Au}-\mathrm{Ag}-\mathrm{Cu}-\mathrm{Pd}$ alloy with In additions. Gold Bull 41:257-263

15. Khalaff K, Schubert K (1974) Kristallstruktur von $\mathrm{Pd}_{5} \mathrm{Ga}_{2}$. J LessCommon Metals 37:129-140 